\title{
An efficient approach for the isolation, identification and evaluation of antimicrobial plant components on an analytical scale, demonstrated by the example of Radix imperatoriae
}

\author{
O. Gökay • D. Kühner • M. Los • F. Götz • U. Bertsche • \\ K. Albert
}

Received: 18 May 2010 /Revised: 11 August 2010 /Accepted: 19 August 2010

(C) Springer-Verlag 2010

\begin{abstract}
Using Radix imperatoriae (the root of masterwort) as an example, we describe an efficient approach for the isolation, identification and evaluation of bioactive plant components on an analytical scale. The extraction of Radix imperatoriae with ethyl acetate was enhanced by the application of ultrasound oscillations. This rhizome extract was applied to three pathogenic bacteria (Bacillus cereus, Escherichia coli, and Staphylococcus aureus) to determine its antimicrobial activity. Disk diffusion was utilized to determine susceptibility. The extract components were separated using a series of chromatography approaches (semi-preparative RP-HPLC, or RP-HPLC on an analytical scale), followed by testing. All fractions were analyzed by LC-UV-ESI-MS and $600 \mathrm{MHz}$ microcoil ${ }^{1} \mathrm{H}$ NMR spectroscopy. Among other findings, in the fraction with the highest antibacterial activity we were able to
\end{abstract}

O. Gökay $\cdot$ K. Albert $(\bowtie)$

Institute of Organic Chemistry,

University of Tübingen,

Auf der Morgenstelle 18,

72076 Tübingen, Germany

e-mail: klaus.albert@uni-tuebingen.de

D. Kühner · F. Götz $\cdot$ U. Bertsche

Institute of Microbiology and Infectious Diseases,

University of Tübingen,

Auf der Morgenstelle 28,

72076 Tübingen, Germany

\section{Los}

Interfaculty Institute for Biochemistry, University of Tübingen, Hoppe-Seyler-Strasse 4,

72076 Tübingen, Germany identify oxypeucedanin and oxypeucedanin hydrate. Subsequent analysis revealed that only oxypeucedanin hydrate had antibacterial activity, whereas oxypeucedanin itself was inactive at the concentrations applied. Furthermore, oxypeucedanin hydrate appears to be largely, or exclusively, a by-product of sample preparation, since it is either not synthesized by the plant as a second metabolite or is produced by it in only very small quantities.

Keywords Radix imperatoriae Peucedanum ostruthium . Antimicrobial activity $\cdot$ LC-ESI-MS $\cdot$ Microcoil NMR

\section{Introduction}

The use of medicinal plants is as old as human civilization, and continuous efforts are being made to improve medicinal plants or produce their products in large amounts through various technologies. About 200,000 natural products of plant origin are known, and many more are being identified from higher plants and microorganisms. Some plant-based drugs have been used for centuries, and for many other plant-based drugs there are no alternative medicines (for example cardiac glycosides [1]).

Peucedanum ostruthium (Imperatoria ostruthium) was of significant importance in nineteenth-century medical science. The alcohol extract of its rhizome (Radix imperatoriae), named Remedium divinum hoffmannii, has been used medically as a stimulant, a stomachicum, a diuretic for chronic indigestion, as well as a therapeutic for typhoid, intermittent fever, paralytic conditions, and in delirium 
tremens. Outwardly, the drug was applied as a powder for ulcers and cancer. Indeed, the plant owes its name "Imperatoria" to these versatile healing properties [2].

The rhizome of Peucedanum ostruthium was found to contain a wide variety of furanocoumarins, such as peucedanin, oxypeucedanin, isooxypeucedanin, oxypeucedanin hydrate, tert- $O$-methyl-oxypeucedanin, pabulenon, peucenin, imperatorin and isoimperatorin [3-7]. Relatively elaborate studies on this plant were conducted several decades ago. At least $400 \mathrm{~g}$ of plant material were extracted with several liters of solvent $[2,5,7]$. Characterization was then performed by means of melting point determination, titration, thin-layer chromatography, preparative chromatography, UV and IR spectroscopy, conventional nuclear magnetic resonance (NMR) spectroscopy, and mass spectrometry [2, 3, 5]. At that time, relatively large sample amounts were necessary for some of these investigations. Tremendous progress in instrumental analytics has since amplified the choices available for chromatographic separation, mass spectrometric analysis, and nuclear magnetic resonance spectroscopic analysis [8-11]. Using these modern analytical techniques, it is possible to comprehensively analyze known and unknown components of biological samples. Thus, the aim of isolating, identifying and quantifying biologically active compounds may be achieved by utilizing high-performance liquid chromatography (HPLC), gas chromatography (GC), mass spectrometry (MS) based on electron ionization (EI), electrospray ionization (ESI), atmospheric-pressure chemical ionization (APCI), or a combination thereof. In comparison with MS, NMR (nuclear magnetic resonance) spectroscopy has at least two notable advantages-it facilitates the identification of all structural and geometrical configurations of compounds, and it also produces signals that correlate directly and linearly with compound abundance [12, 13]. However, NMR spectroscopy normally has a relatively low sensitivity, and accordingly only the most abundant species can generally be detected [14]. On the other hand, mass spectrometry, when combined with effective sample preparation and chromatographic separation, has high sensitivity and specificity, as well as a good dynamic range [15-18]. Nowadays, microtechniques like microcoil ${ }^{1} \mathrm{H}$ NMR spectroscopy are much more sensitive and allow measurements of sample amounts in the low nmol range. They can also be coupled with capillary HPLC (highperformance liquid chromatography) or GC (gas chromatography) systems [19-21]. The HPLC-NMR or even HPLC-NMR-MS capillary technique offers a reliable analysis of unstable, light- or air-sensitive compounds in the continuous- or stopped-flow mode, and the wasteful collection of HPLC fractions, the time-consuming removal of almost nonvolatile solvents and the risk of contamination can be avoided.

\section{Experimental}

Samples

The roots of Peucedanum ostruthium were obtained from the Institute of Botany at the University of Tübingen (Tübingen, Germany)

\section{Chemicals}

$\mathrm{CHCl}_{3}-\mathrm{d}_{1}$ (NMR grade), dimethyl sulfoxide (DMSO, LiChrosolve), ethyl acetate (LiChrosolve) and methanol (LiChrosolve) were purchased from Merck (Darmstadt, Germany). Water was obtained from a Milli-Q water purification system (Millipore AS, Bedford, MA, USA). Mueller Hinton agar plates were purchased from Oxoid GmbH (Wesel, Germany). LB (lysogeny broth) liquid medium and kanamycin were obtained from Sigma-Aldrich (München, Germany). Bacterial strains-Bacillus cereus (ATCC No. 14579), Escherichia coli (ATCC No. 25922) and Staphylococcus aureus (ATCC No. 29213)-were purchased from LGC Standards GmbH (Wesel, Germany).

\section{Preparation of the crude extract}

The air-dried Imperatoria roots were crushed by the use of a mortar and pestle. One gram of the sample was inserted into a glass flask and $3 \mathrm{~mL}$ ethyl acetate were added. The flask was placed into an ultrasonic bath (Sonorex RK 31, Bandelin Electronic KG, Berlin, Germany). The sample was extracted twice with $3 \mathrm{~mL}$ ethyl acetate $(2 \times 30 \mathrm{~min})$ at $50{ }^{\circ} \mathrm{C}$; the ultrasound oscillation amplitude was set to $70 \%$. The extracts were combined afterwards. The solvent was removed by evaporation in a vacuum oven $(30 \mathrm{mmHg}$ and $25{ }^{\circ} \mathrm{C}$ ), and the dry weight was determined. The sample was then dissolved in dimethyl sulfoxide and a concentration of $25 \mathrm{mg} \mathrm{mL}^{-1}$ was achieved. The solution was filtered through a $0.2 \mu \mathrm{m}$ membrane filter (Whatman $\mathrm{GmbH}$, Dassel, Germany) for semi-preparative reversed-phase high-performance liquid chromatography. For the thermal treatment experiment, the extraction was performed as described above but at room temperature instead.

Chromatographic conditions

\section{Semi-preparative HPLC}

Instrument: Agilent 1100 series high-performance liquid chromatograph (Agilent Tech., Waldbronn, Germany), equipped with a diode array detector; detection wavelength $220 \mathrm{~nm}$, slit width $16 \mathrm{~nm}$. The instrument was equipped with a Prontosil 120-10-C18 SH, $10.0 \mu \mathrm{m}(250 \times 10.0 \mathrm{~mm}$ 
ID) column (Bischoff;,Leonberg, Germany). The manually injected volume was $50 \mu \mathrm{L}$ of the crude (ethyl acetate) extract with a concentration of $25 \mathrm{mg} \mathrm{mL}^{-1}$, which was passed through a $50 \mu \mathrm{L}$ loop, flow rate $2 \mathrm{~mL} \mathrm{~min}^{-1}, 25 \pm$ $1{ }^{\circ} \mathrm{C}$ column temperature. Reservoir A contained water (with $0.1 \%$ acetic acid); reservoir B contained methanol. A 30 min binary linear gradient was employed: $100 \% \mathrm{~A}$ in $0 \mathrm{~min}, 100 \% \mathrm{~B}$ in $30 \mathrm{~min}$, followed by isocratic elution with $100 \%$ B for the last 15 min. Twenty peak fractions were collected manually according to the elution profile.

\section{HPLC with the analytical column}

Instrument: Agilent 1100 series high-performance liquid chromatograph (Agilent Tech., Waldbronn, Germany), equipped with a diode array detector; detection wavelength $220 \mathrm{~nm}$, slit width $16 \mathrm{~nm}$. The instrument was equipped with a Prontosil 300-3-C30, $3.0 \mu \mathrm{m}(250 \times 4.6 \mathrm{~mm}$ ID) column (Bischoff, Leonberg, Germany). The manually injected volume was $50 \mu \mathrm{L}$ of the bactericidal fraction with a concentration of $1.08 \mathrm{mg} \mathrm{mL}^{-1}$ through a $50 \mu \mathrm{L}$

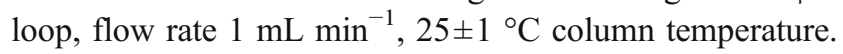
Reservoir A contained water (with $0.1 \%$ acetic acid), reservoir B contained methanol. A linear gradient from $100 \%$ A to $100 \%$ B in 30 min was employed, followed by an isocratic elution with $100 \% \mathrm{~B}$ for the last $3 \mathrm{~min}$.

\section{Sample preparation for NMR spectroscopy}

Fraction 11, collected from seven semi-preparative HPLC runs (see section "Semi-preparative HPLC"), was heat treated at $60{ }^{\circ} \mathrm{C}$ for $2.5 \mathrm{~h}$ to promote the transformation of oxypeucedanin into oxypeucedanin hydrate (which is initially present in only a small quantity). Afterwards, the solution (in methanol) was concentrated by evaporation in a vacuum oven $\left(30 \mathrm{mmHg}\right.$ and $\left.25^{\circ} \mathrm{C}\right)$ to a total volume of $350 \mu \mathrm{L}$. Fifty microliters of the solution were injected into the HPLC system. This procedure was repeated seven times, and each of the two fractions was collected manually from seven HPLC runs according to the elution profile. The corresponding fractions were pooled to obtain enough material for further investigations. Finally, the solvent (methanol) was evaporated in a vacuum oven $\left(30 \mathrm{mmHg}, 25^{\circ} \mathrm{C}\right)$, and the dry residues were dissolved in $15 \mu \mathrm{L}$ deuterated chloroform before performing the NMR experiments.

\section{$R P C_{30}$ HPLC-UV-ESI-MS analysis}

The liquid chromatography system consisted of an Agilent 1100 series high-performance liquid chromatograph (Agilent Tech.; Waldbronn, Germany), equipped with a diode array detector. The separation was performed on a reversed-phase
Prontosil 300-3-C30, $3.0 \mu \mathrm{m}(250 \times 4.6 \mathrm{~mm}$ ID) column (Bischoff, Leonberg, Germany). The LC system was operated using a mobile phase consisting of water with $0.1 \%$ acetic acid (Reservoir A) and methanol (Reservoir B). A linear gradient from $100 \%$ A to $100 \%$ B in $30 \mathrm{~min}$ was employed, followed by an isocratic elution with $100 \% \mathrm{~B}$ for the last $15 \mathrm{~min}$. The flow rate was set to $0.5 \mathrm{~mL} \mathrm{~min}{ }^{-1}$. Injection of the sample (50 $\mu \mathrm{L}$ with a concentration of $36 \mu \mathrm{g} \mathrm{mL}^{-1}$ ) was performed manually through a $50 \mu \mathrm{L}$ loop, and the column was kept in an oven set to $25 \pm 1^{\circ} \mathrm{C}$. The detection wavelength was set to $220 \mathrm{~nm}$, with a slit width of $16 \mathrm{~nm}$.

The mass spectrometric detection was achieved with a Agilent MSD ion trap mass spectrometer (Agilent Tech., Waldbronn, Germany), using electrospray ionization (ESI) operated in the positive ionization mode at a potential of $4.0 \mathrm{kV}$ (on the discharge needle). The spectrometer was fitted with an ESI interface. The desolvation temperature was set to $400{ }^{\circ} \mathrm{C}$ in the ESI probe, and the ion source temperature was set to $125^{\circ} \mathrm{C}$. Nitrogen was used as collision gas. The nitrogen desolvation flow rate was set to $800 \mathrm{~L} \mathrm{~h}^{-1}$ and the nebulizer pressure was set to $60 \mathrm{psi}$. The cone voltage was set to $30 \mathrm{~V}$, and a collision energy of $20 \mathrm{eV}$ was applied. The mass spectrometric data were acquired in the range $m / z \quad 100-800$. Fragmentor, gain and threshold were set to $70,1.0$ and 150 , respectively.

\section{NMR measurements}

${ }^{1} \mathrm{H}$ NMR spectra were recorded on a Bruker AMX 600 spectrometer from Bruker Biospin (Rheinstetten, Germany) operating at a proton frequency of $600.13 \mathrm{MHz}$ and a temperature of $298 \mathrm{~K}$. The samples were injected using a $50 \mu \mathrm{L}$ Hamilton syringe into a microcoil NMR probe (Protasis-MRM, Savoy, IL, USA) with an active detection volume of $1.5 \mu \mathrm{L}$. One hundred fifty micrograms of oxypeucedanin and $220 \mu \mathrm{g}$ of oxypeucedanin hydrate were each dissolved in $15 \mu \mathrm{L}$ deuterated chloroform $\left(\mathrm{CDCl}_{3}\right)$. The deuterium signal of $\mathrm{CDCl}_{3}$ was used for locking and shimming the magnetic field. The pulse program zg30 was selected as the pulse program, and the following parameters were set: 32 transients; acquisition time $2.75 \mathrm{~s} ; 1.0 \mathrm{~s}$ relaxation delay; 32768 time domain points; sweep width $8.90 \mathrm{ppm}(5340 \mathrm{~Hz})$. The total acquisition time was $2 \mathrm{~min}$ 20 s. FIDs were Fourier transformed with $0.3 \mathrm{~Hz}$ line broadening (LB).

The resulting spectra were manually phased and the baselines were also corrected manually. NMR experiments were controlled by the software XWIN-NMR from Bruker (Bruker Biospin, Rheinstetten, Germany). Topspin (Bruker Biospin, Rheinstetten, Germany) was used as the software for processing the recorded spectra. 
Preparation of the fractions $11 \mathrm{a}$ and $11 \mathrm{~b}$ for antimicrobial screening

After finishing NMR experiments (see section "NMR measurements"), samples $11 \mathrm{a}$ and $11 \mathrm{~b}$ were collected from the NMR probe and the deuterated chloroform $\left(\mathrm{CDCl}_{3}\right)$ was removed by evaporation under nitrogen at room temperature. Each sample was then dissolved in $10 \mu \mathrm{L}$ DMSO. Thus, a concentration of about $15 \mathrm{mg} \mathrm{mL}^{-1}$ for oxypeucedanin hydrate (11a) and $22 \mathrm{mg} \mathrm{mL}^{-1}$ for oxypeucedanin (11b) could be achieved for the antimicrobial test. Sterile paper disks (Whatman No. 40; $6.0 \mathrm{~mm}$ in diameter) were soaked with $10 \mu \mathrm{L}$ of the crude extract, the collected fractions or the isolated compounds, and placed on the surface of the inoculated MH (Mueller-Hinton) agar plates.

\section{Determination of antimicrobial activity}

In this work, agar disk diffusion was the method of choice for antimicrobial screening [22-24].

The bacterial strains were inoculated from a glycerol freezing culture in $100 \mathrm{~mL} \mathrm{LB}$ (lysogeny broth) medium and incubated overnight at $37{ }^{\circ} \mathrm{C}$ in a shaker. Prior to the experiments, the bacteria suspensions were diluted 1:4. One hundred microliters of bacterial suspension were spread over the surfaces of the $\mathrm{MH}$ agar plates.

The solvent (ethyl acetate) of the crude Radix imperatoriae extract was removed by evaporation under nitrogen at room temperature, and the dry extract was dissolved in DMSO. A concentration of $25 \mathrm{mg} \mathrm{mL}^{-1}$ was achieved.

The solvent (methanol) of the 20 fractions collected from three semi-preparative HPLC runs was evaporated in a vacuum oven $\left(30 \mathrm{mmHg}\right.$ and $\left.25^{\circ} \mathrm{C}\right)$, and the dry extracts were dissolved in $10 \mu \mathrm{l}$ DMSO. These solutions were applied onto the MH agar plate. In the same way, the solutions of the fractions $11 \mathrm{a}$ and $11 \mathrm{~b}$ were applied onto the MH agar plate.

The agar plates were incubated at $37^{\circ} \mathrm{C}$ for $24 \mathrm{~h}$, and the zones of growth inhibition were measured. All tests were performed in triplicate. The effects of dimethyl sulfoxide (DMSO) and the antibiotic kanamycin $(4 \mu \mathrm{L}, c=$ $5 \mu \mathrm{g} \mathrm{mL}^{-1}$ ) on the microbial growth were also analyzed as a negative and positive test, respectively.

\section{Results and discussion}

Although the vast majority of bacteria are harmless or beneficial, quite a few bacteria are pathogenic. As some pathogenic bacteria can cause skin infections, pneumonia, meningitis, sepsis, a systemic inflammatory response producing shock, massive vasodilation, and even death, it is imperative to continue searching for antibacterial agents. The most commonly used technique for antibacterial susceptibility testing is the disk diffusion method.

It is for this reason that the susceptibilities of three pathogenic bacteria (Bacillus cereus, Escherichia coli, and Staphylococcus aureus) to the crude (ethyl acetate) extract of Peucedanum ostruthium were investigated by the agar disk diffusion method, which proved to be a fast semiquantitative tool. Sterile paper disks were soaked with 10 $\mu \mathrm{L}$ of the extract at a concentration of $25 \mathrm{mg} \mathrm{mL}^{-1}$. The extract-treated disks only produced an appreciable inhibition zone (about $6.0 \mathrm{~mm}$ in diameter) on the Bacillus cereus lawn (Fig. 1).

Fifty microliters of the crude (ethyl acetate) extract at a concentration of $25 \mathrm{mg} \mathrm{mL}^{-1}$ (in DMSO) were loaded onto a semi-preparative $\mathrm{C}_{18}$ RP HPLC column and monitored at UV $220 \mathrm{~nm}$. Twenty fractions were collected from the HPLC effluent. This step was repeated ten times, and each of the 20 fractions from three HPLC runs was pooled to get enough material for the bioassay. The elution profile and fractionation of the crude extract are shown in Fig. 2. The solvent was removed by evaporation in a vacuum oven at $25{ }^{\circ} \mathrm{C}$. Each fraction was redissolved in $10 \mu \mathrm{L}$ dimethyl sulfoxide. Agar disk diffusion was performed once again as the screening method. The disk soaked with $10 \mu \mathrm{L}$ of the solution of fraction 11 (in DMSO) at a concentration of 16.2 $\mu \mathrm{g} \mu \mathrm{L}^{-1}$ (collected from three HPLC runs), which corresponds to the second major peak (retention time $32.2 \mathrm{~min}$ ) in Fig. 2, was found to be the only inhibitory agent for the crude extract, as it produced a large inhibition halo $9.0 \mathrm{~mm}$ in diameter on the Bacillus cereus lawn (Fig. 1). The other fractions did not show any antimicrobial activity against the three pathogenic bacteria at the applied concentrations (results not shown).

HPLC-MS was used to determine the components of fraction 11 . Fifty microliters of the fraction (at a concen-

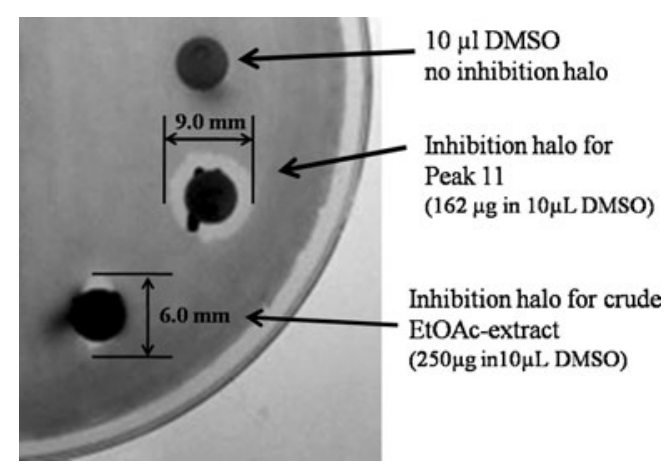

Fig. 1 Inhibition zones detected on the Bacillus cereus lawn obtained for $10 \mu \mathrm{L}$ DMSO (as a negative control), fraction 11 (3 runs, $162 \mu \mathrm{g}$ in $10 \mu \mathrm{L}$ DMSO) of the chromatogram in Fig. 2, and $10 \mu \mathrm{L}$ of the Radix imperatoriae (crude) ethyl acetate extract $(250 \mu \mathrm{g}$ in $10 \mu \mathrm{L}$ DMSO) 
Fig. 2 Elution profile and fractionation of Radix imperatoria ethyl acetate (crude) extract on the RP $\mathrm{C}_{18}$ SH semi-preparative HPLC column. UV detected at $220 \mathrm{~nm}$. Column: Bischoff 120-10-C18 SH, $10 \mu \mathrm{m}$, $250 \times 10.0 \mathrm{~mm}$ I.D. The arrow indicates antibacterial fraction 11

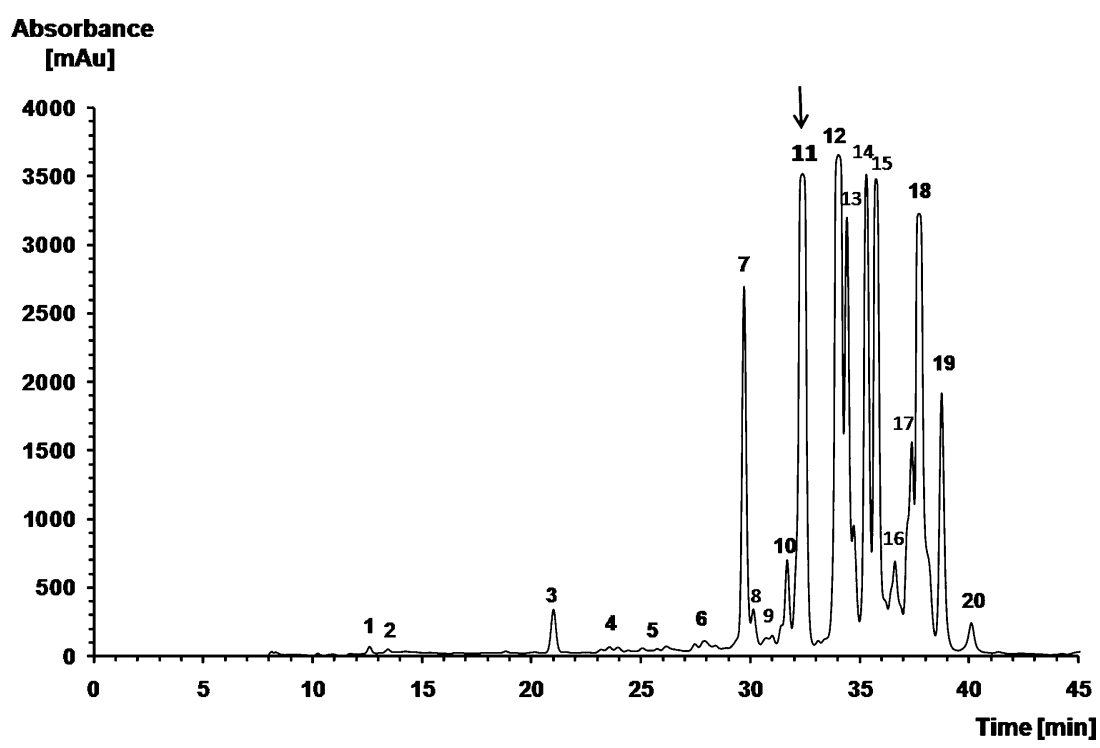

tration of $36 \mathrm{mg} \mathrm{mL}^{-1}$ in methanol) were separated by means of a highly shape-selective RP $\mathrm{C}_{30}$ HPLC column $[25,26]$, and the analytes were detected on-line by mass spectrometry equipped with an ESI source, using the positive ionization mode. The results showed that ESI offers high sensitivity for both of the detected components: oxypeucedanin hydrate and oxypeucedanin (Fig. 3). These two compounds were found to form exclusively quasimolecular ions $[\mathrm{M}+\mathrm{H}]^{+}$at $\mathrm{m} / z 305$ (for oxypeucedanin hydrate) and $\mathrm{m} / \mathrm{z} 287$ (for oxypeucedanin), both with $100 \%$ abundance. Figure 4 shows the product ion mass spectra of the $[\mathrm{M}+\mathrm{H}]^{+}$ion of oxypeucedanin hydrate (left) and oxypeucedanin (right). The investigated retention times for oxypeucedanin hydrate and oxypeucedanin were $29.6 \mathrm{~min}$ and $31.9 \mathrm{~min}$, respectively (Fig. 3).

To determine whether oxypeucedanin hydrate is synthesized by the plant itself or appears as a transformation product of oxypeucedanin due to the opening of the oxirane ring and hydrolysis during the extraction procedure, thermal experiments were carried out. Therefore samples of fraction 11, with a concentration of $36 \mathrm{mg} \mathrm{mL}^{-1}$ (in methanol), were taken after $1 \mathrm{~h}$ at $30{ }^{\circ} \mathrm{C}, 1.5 \mathrm{~h}$ at $60{ }^{\circ} \mathrm{C}$, $2.5 \mathrm{~h}$ at $60{ }^{\circ} \mathrm{C}$ and $3.5 \mathrm{~h}$ at $60{ }^{\circ} \mathrm{C}$, and injected into an HPLC chromatograph for analysis. In Fig. 5, four stacked chromatograms show different HPLC peak area ratios of the compounds $11 \mathrm{a}$ and $11 \mathrm{~b}$ obtained by thermal treatment for different time periods. In this investigation, increasing the temperature or duration of treatment decreased the signal area of $11 \mathrm{~b}$ (oxypeucedanin) and increased the peak area of 11a (oxypeucedanin hydrate). After $1 \mathrm{~h}$ at $30^{\circ} \mathrm{C}$, just after extraction, the signal area ratio $(11 \mathrm{a} / 11 \mathrm{~b})$ was 0.01 . On the other hand, a signal area ratio $(11 \mathrm{a} / 11 \mathrm{~b})$ of 1.90 could be ascertained for the sample after treatment at $60{ }^{\circ} \mathrm{C}$ for $3.5 \mathrm{~h}$. These results lead to the presumption that oxypeucedanin hydrate is either not synthesized by the plant itself as a second metabolite or is produced by it in only very small quantities.

To achieve unambiguous evaluation and identification of the two separated compounds, ${ }^{1} \mathrm{H}$ NMR spectroscopy experiments were performed (since this is the most effective technique).

Due to the relatively small amount collected from the seven semi-preparative HPLC runs $(387 \mu \mathrm{g})$ followed by the separation on a HPLC $\mathrm{C}_{30}$ column, the spectra could not be recorded on a NMR spectrometer equipped with a conventional probe. This problem could be bypassed by

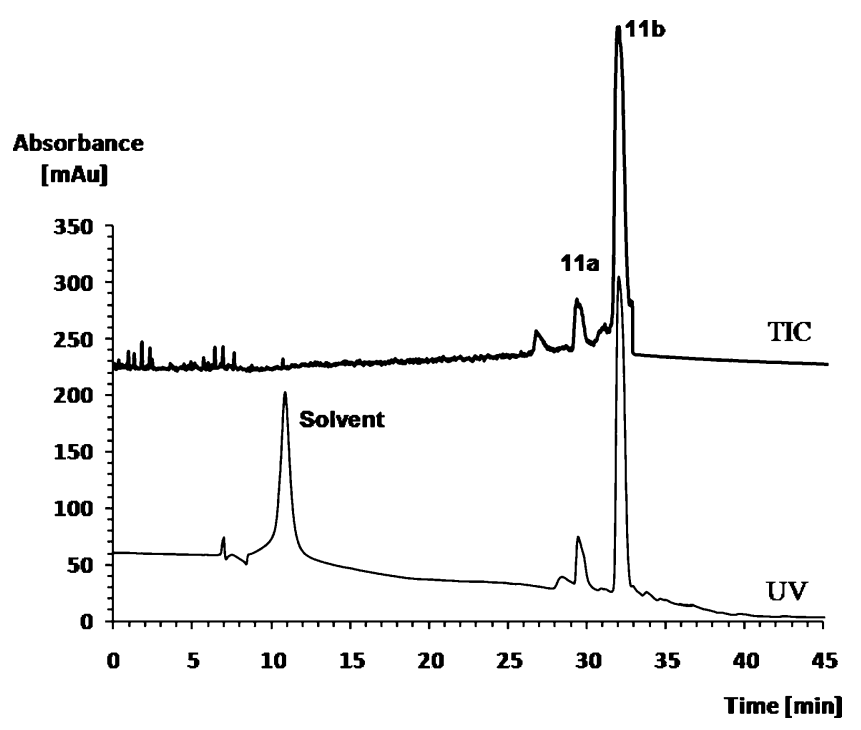

Fig. 3 HPLC-UV-ESI-MS (positive ionization mode) analysis of fraction 11 in Fig. 2 (after $1 \mathrm{~h}$ at $30^{\circ} \mathrm{C}$ in methanol). Total ion current (TIC) and UV $(220 \mathrm{~nm})$ spectrum. 11a $=$ oxypeucedanin hydrate, $11 \mathrm{~b}=$ oxypeucedanin. Inj. vol. $50 \mu \mathrm{L}\left(c=36 \mu \mathrm{g} \mathrm{m}^{-1}\right.$, in methanol). Column: Bischoff 300-3-C30, $3 \mu \mathrm{m}, 250 \times 4.6 \mathrm{~mm}$ I.D. 
Fig. 4 Full mass spectra (electrospray ionization, positive ionization mode) of oxypeucedanin hydrate (peak 11a) and oxypeucedanin (peak 11b) with their principal fragmentation obtained from the online HPLC-ESI-MS analysis shown in Fig. 3

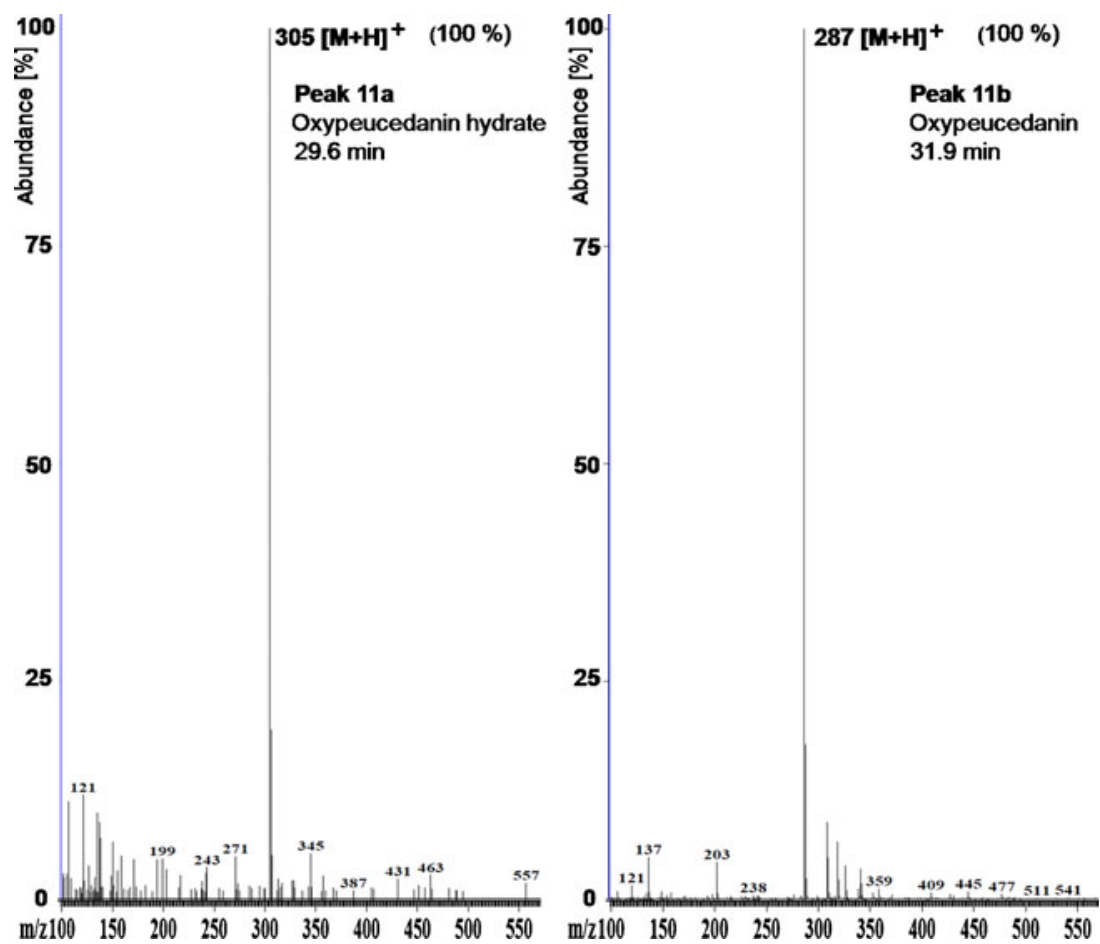

accomplishing microcoil ${ }^{1} \mathrm{H}$ NMR spectroscopy, which allows the detection of analytes in the nmol range that are injected into a selenoidal microprobe with an active detection cell volume of $1.5 \mu \mathrm{l}$.

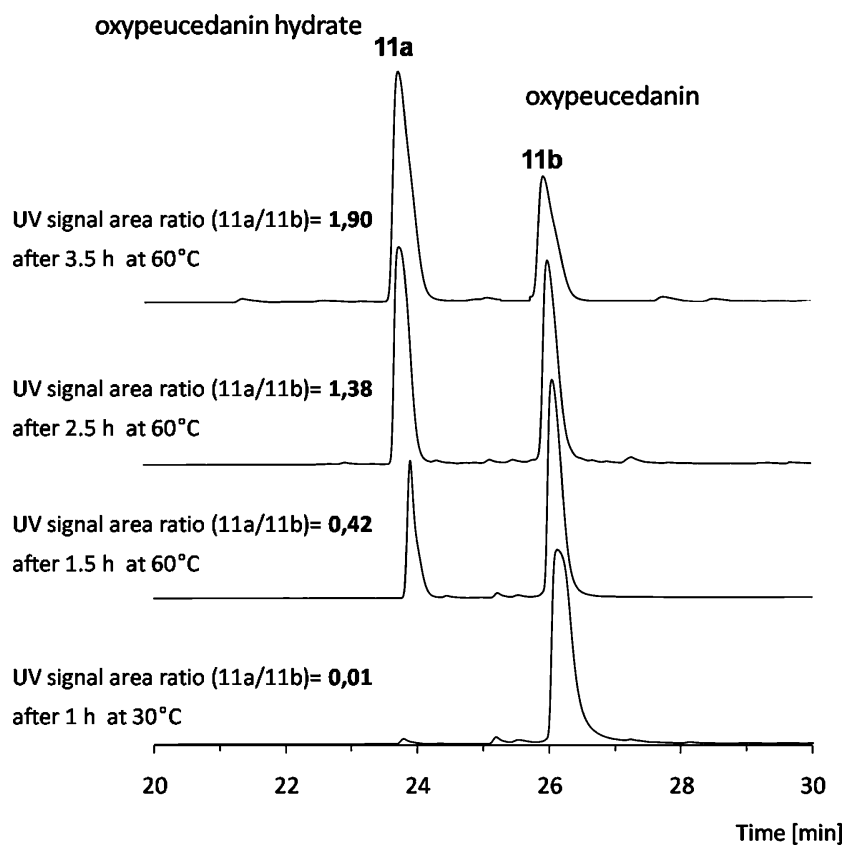

Fig. 5 HPLC chromatograms for fraction 11 in Fig. 2 (in methanol) after thermal treatment $\left(30^{\circ} \mathrm{C}\right.$ for $1 \mathrm{~h}, 60{ }^{\circ} \mathrm{C}$ for $1.5 \mathrm{~h}, 60{ }^{\circ} \mathrm{C}$ for $2.5 \mathrm{~h}$ and $60{ }^{\circ} \mathrm{C}$ for $3.5 \mathrm{~h}$ ). UV detected at $220 \mathrm{~nm} .11 \mathrm{a}=$ oxypeucedanin hydrate, $11 \mathrm{~b}=$ oxypeucedanin. Column: Bischoff 300-3-C30, $3 \mu \mathrm{m}$, $250 \times 4.6 \mathrm{~mm}$ I.D.
${ }^{1} \mathrm{H}$ signals appearing in the spectra of both of the isolated compounds oxypeucedanin hydrate (Fig. 6) and oxypeucedanin (Fig. 7) due to protons attached to carbon atoms can be assigned as follows. Signal 4 is a doublet produced by the methine group proton attached to the carbon atom 4 at $6.32 \mathrm{ppm}$. Signal 5 appears due to the methine group proton on carbon atom 5 between 8.20 and 8.19 ppm. Signal 9 represents a doublet and arises from the methine proton attached to the carbon atom 9 between 7.00 and $6.99 \mathrm{ppm}$. Signal 10, between 7.61 and $7.60 \mathrm{ppm}$, can be assigned to the methine group proton on carbon atom 10. Signal 13, appearing between 7.20 and $7.17 \mathrm{ppm}$, can be attributed to the methine proton attached to carbon atom 13. The NMR signals assigned above $(4,5,9,10,13)$ with their related chemical shift values are typical of the psoralen skeleton, and are italicized in Table 1. The following signals are induced by protons attached to the carbon atoms in the alkoxy sidechain of the peucedanins. Since they have the same direct atomic neighbors or a similar chemical environment of methylene group 16 in both sidechains, the signals $\mathrm{H}_{1}-16$ and $\mathrm{H}_{2}-16$ arising from the methylene protons have almost the same chemical shift values of 4.45-4.40 ppm (doublet) and 4.55-4.53 ppm (doublet), respectively, in both compounds.

Signal 17, which appears at 3.92 ppm for oxypeucedanin hydrate and at $3.27 \mathrm{ppm}$ for oxypeucedanin, can be assigned to the proton attached to carbon atom 17 . The signals 19 and 22 from oxypeucedanin hydrate are both singlets, and are induced by the methyl group protons on 
Fig. $6600 \mathrm{MHz}$ microcoil ${ }^{1} \mathrm{H}$ NMR spectrum of oxypeucedanin hydrate (peak 11a) in $\mathrm{CDCl}_{3}$. The signal numbers agree with those in Table 1

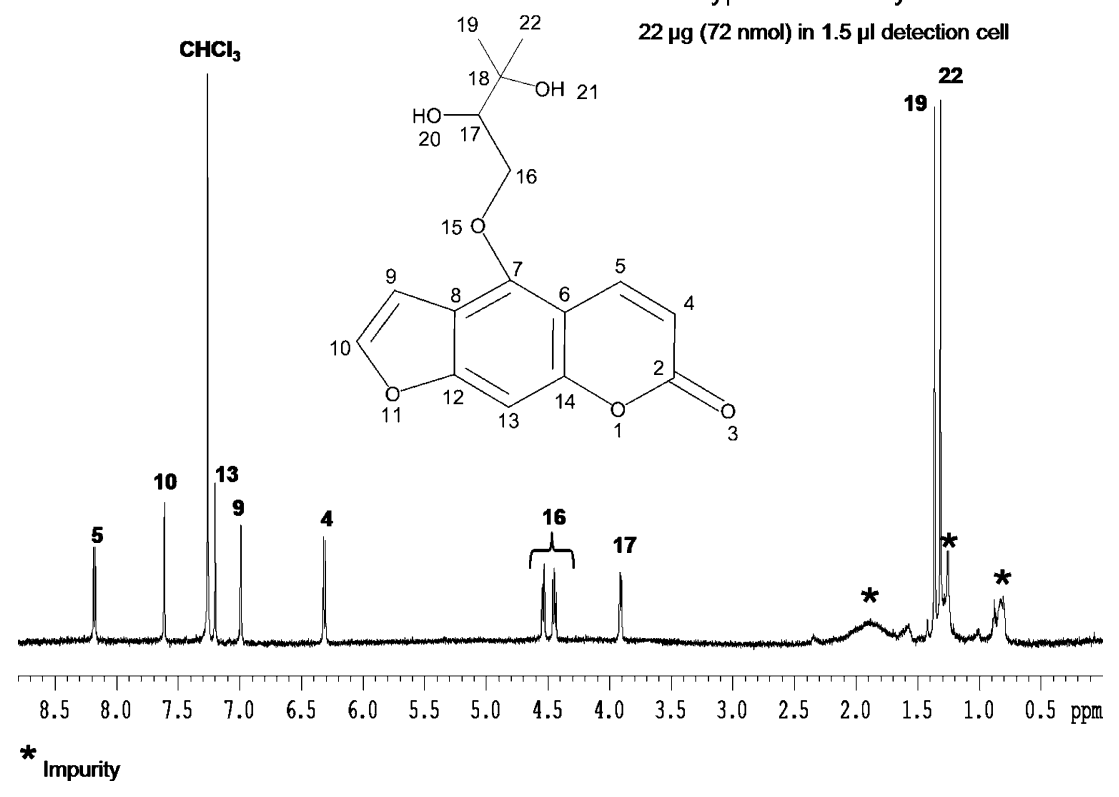

carbon atoms 19 and 22 at $1.36 \mathrm{ppm}$ and $1.32 \mathrm{ppm}$, respectively.

The oxypeucedanin signals 20 (singlet) and 21 (singlet) that appear at $1.41 \mathrm{ppm}$ and $1.33 \mathrm{ppm}$ are due to the methyl group protons attached to carbon atoms 20 and 21, respectively. The signal assignments are listed in Table 1.

The inhibitory effect of the isolated oxypeucedanin hydrate was also determined by the disk diffusion method. An amount of $220 \mu \mathrm{g}$ of this compound produced an inhibition halo $10.0 \mathrm{~mm}$ in diameter. Figure $8 \mathrm{a}$ shows a typical Bacillus cereus inhibition halo obtained for oxypeucedanin hydrate. On the other hand, Escherichia coli and Staphylococcus aureus showed no sensitivity to the Radix imperatoriae ethyl acetate extract. Thus, no inhibition zone was detected on the two investigated bacteria lawns. For oxypeucedanin, no inhibition zone could be detected on Bacillus cereus, Escherichia coli, and Staphylococcus aureus (results not shown). As a consequence, this compound does not have any apparent antimicrobial effect on these bacteria at the applied concentration $\left(15 \mathrm{mg} \mathrm{mL}^{-1}\right)$. Four microliters
Fig. $7600 \mathrm{MHz}$ microcoil ${ }^{1} \mathrm{H}$ NMR spectrum of oxypeucedanin (peak 11b) in $\mathrm{CDCl}_{3}$. The signal numbers agree with those in Table 1

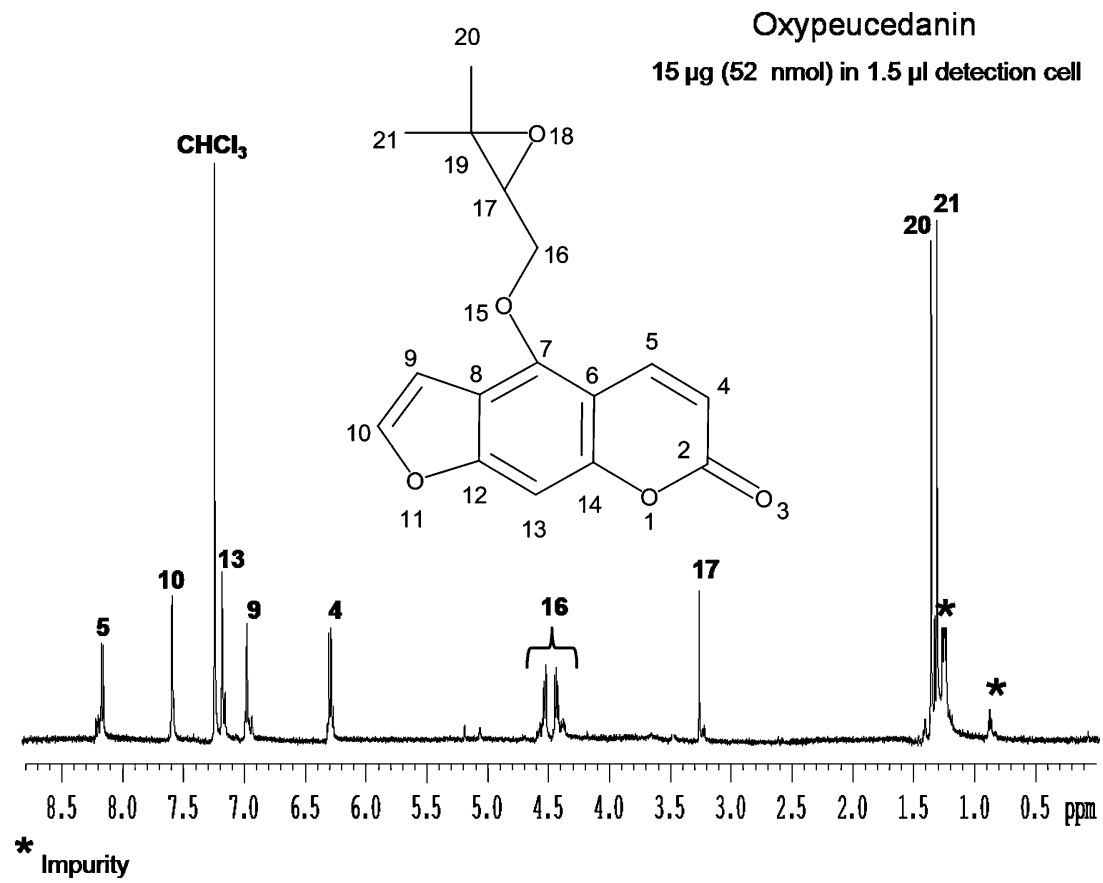


Table 1 Chemical shift values of oxypeucedanin hydrate (peak 11a) and oxypeucedanin (peak $11 \mathrm{~b})$ obtained by performing $600 \mathrm{MHz}$ microcoil ${ }^{1} \mathrm{H}$ NMR spectroscopy. Many peucedanin derivatives have the italicized shift values for their psoralen skeletons in common

\begin{tabular}{|c|c|c|c|c|c|}
\hline \multicolumn{3}{|c|}{ Oxypeucedanin hydrate } & \multicolumn{3}{|c|}{ Oxypeucedanin } \\
\hline Group & $\mathrm{nH}$ & Shift[ppm] & Group & $\mathrm{nH}$ & Shift[ppm] \\
\hline $\mathrm{H}-22$ & 3 & $1.32(\mathrm{~s})$ & $\mathrm{H}-21$ & 3 & $1.33(\mathrm{~s})$ \\
\hline $\mathrm{H}-19$ & 3 & $1.36(\mathrm{~s})$ & $\mathrm{H}-20$ & 3 & $1.41(\mathrm{~s})$ \\
\hline $\mathrm{H}-17$ & 1 & $3.92(\mathrm{dd}, 7.6,2.6)$ & $\mathrm{H}-17$ & 1 & $3.27(\mathrm{~s})$ \\
\hline $\mathrm{H}_{1}-16$ & 1 & $4.45(\mathrm{dd}, 9.5,7.9)$ & $\mathrm{H}_{1}-16$ & 1 & $4.40(\mathrm{dd}, 9.2,1.3)$ \\
\hline $\mathrm{H}_{2}-16$ & 1 & $4.55(\mathrm{dd}, 12.8,2.9)$ & $\mathrm{H}_{2}-16$ & 1 & $4.53(\mathrm{dd}, 9.5,2.6)$ \\
\hline $\mathrm{H}-4$ & 1 & $6.32(d, 9.8)$ & $\mathrm{H}-4$ & 1 & $6.32(d, 9.8)$ \\
\hline $\mathrm{H}-9$ & 1 & $6.99(d, 1.3)$ & H-9 & 1 & $7.00(d, 1.6)$ \\
\hline $\mathrm{H}-13$ & 1 & $7.20(s)$ & $\mathrm{H}-13$ & 1 & $7.17(d, 14.1)$ \\
\hline $\mathrm{H}-10$ & 1 & $7.16(d, 2.3)$ & $\mathrm{H}-10$ & 1 & $7.60(d d, 10.5,2.3)$ \\
\hline $\mathrm{H}-5$ & 1 & $8.19(d, 9.8)$ & $\mathrm{H}-5$ & 1 & $8.20(d d, 27.9,9.5)$ \\
\hline
\end{tabular}

of kanamycin at a concentration of $5 \mu \mathrm{g} \mathrm{mL}^{-1}$ were used as a positive control, and DMSO as a negative control. While no inhibitory effect could be observed for DMSO, kanamycin caused an inhibition zone $14.0 \mathrm{~mm}$ in diameter (Fig. 8b).

\section{Conclusion}

The effects of the main components of the Radix imperatoriae ethyl acetate extract on three pathogenic bacterial strains were successfully investigated using the agar disk diffusion screening method, and the active compound was determined by semi-preparative and analytical HPLC techniques, on-line mass spectrometric detection, and $600 \mathrm{MHz}$ capillary ${ }^{1} \mathrm{H}$ NMR spectroscopy equipped with a ${ }^{1} \mathrm{H}$ selective $1.5 \mu \mathrm{L}$ microcoil probe. The agar disk diffusion method provided a rapid semi-quantitative tool to evaluate the sensitivity of the bacteria lawns to the extract. The results indicate that the isolated psoralen derivative oxypeucedanin hydrate presents significant antimicrobial activity against Bacillus cereus at higher concentrations. Due to the extreme sensitivities of modern analytical techniques, analyte amounts in the nmol range-collected in ten HPLC runs on a semi-preparative $\mathrm{C}_{18} \mathrm{RP}$ column-were sufficient to carry out bioactivity screenings, which were then followed by spectrometric and spectroscopic analyses. Ultimately, it was found that $\mathrm{C}_{18} \mathrm{RP}$ chromatographic material did not facilitate the separation of oxypeucedanin and oxypeucedanin hydrate. However, the highly selective $\mathrm{C}_{30} \mathrm{RP}$ material was able to achieve an adequate separation. Thus, the two compounds could be collected separately for microcoil ${ }^{1} \mathrm{H}$ NMR spectroscopic measurements and antimicrobial screening. By utilizing $\mathrm{C}_{30}$ RP HPLC-UV-ESI-MS coupling, the mass-to-charge ratios $(\mathrm{m} / \mathrm{z})$ of both analytes could be determined reliably. Microcoil proton nuclear magnetic resonance (microcoil ${ }^{1} \mathrm{H}$ NMR) spectra of 1.5 microliter samples were obtained with a high mass sensitivity [signal-to-noise ratio $(\mathrm{S} / \mathrm{N})$ per nanomol]. Fifteen micrograms ( $52 \mathrm{nmol})$ of oxypeucedanin $(22 \mu \mathrm{g}$ of oxypeucedanin hydrate, $\sim 72 \mathrm{nmol}$ ) in the $1.5 \mu \mathrm{L}$ detection cell were sufficient to obtain an unambiguous ${ }^{1} \mathrm{H}$ NMR spectrum in about $2 \mathrm{~min} 20 \mathrm{~s}$. This technique reduces the required sample quantity by a factor of up to 15 in comparison to a $5 \mathrm{~mm}$ tube in a conventional commercial probe. It is for this reason that the microcoil ${ }^{1} \mathrm{H}$ NMR technique proves useful with mass-limited samples and as a detector in capillary separations, as often demonstrated by our group [27-30] and several other very
Fig. 8a-b Inhibition zones detected on the Bacillus cereus lawn for a $10 \mu \mathrm{L}$ DMSO as a negative control and $220 \mu \mathrm{g}$ oxypeucedanin hydrate (in $10 \mu \mathrm{L}$ DMSO) and b $10 \mu \mathrm{L}$ DMSO as a negative control and 20 ng kanamycin (in $4 \mu \mathrm{L}$ DMSO) as a positive control
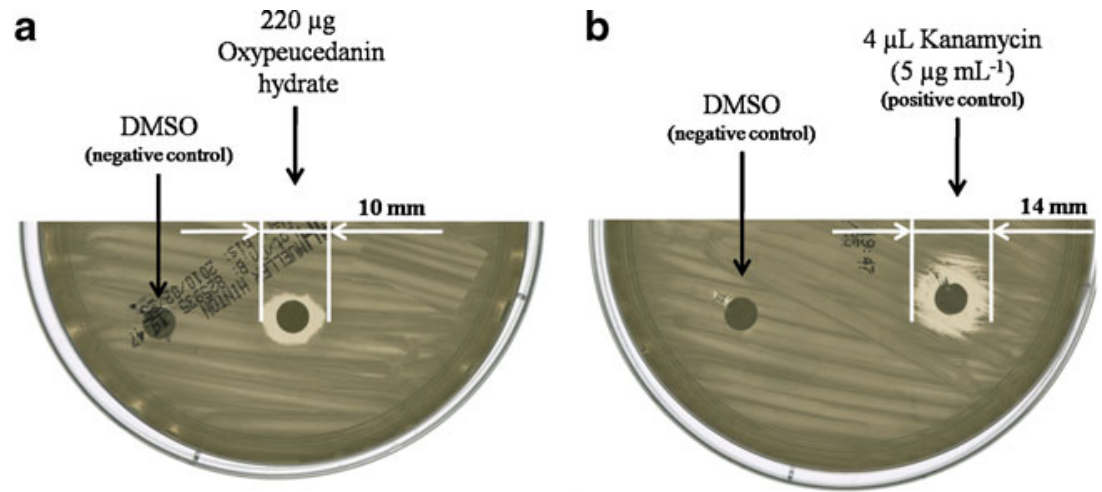
active European groups [31-36]. Moreover, our results confirmed that disk diffusion is a reliable, easy and inexpensive semi-quantitative susceptibility testing method that is sufficiently sensitive and ideally suited for preliminary investigations on the nano- to microscale. Moreover, it was found that oxypeucedanin hydrate is probably not synthesized by the plant itself, but is formed during the extraction or sample preparation process.

Acknowledgements The authors thank the Institute of Botany at the University of Tübingen for supplying them with plant material.

\section{References}

1. Ramawat KG, Merillon JM (eds)(2008) Bioactive molecules and medicinal plants. Springer, Berlin

2. Butenandt A, Marten A (1932) Über die Inhaltsstoffe der Meisterwurz (Imperatoria Ostruthium). Wiley-VCH, Weinheim, pp 187-210

3. Khaled SA, Szendrli K, Novak I (1974) Phytochemistry 14:14611462

4. Hiermann A, Schantl D, Zsilavecz MS, Reine J (1996) Phytochemistry 43:881-883

5. Reisch J, Khaled SA, Szendrei K, Novak I (1975) Phytochemistry 14:1889-1890

6. Hörhammer L, Wagner H, Heydweiller D (1969) Phytochemistry $8: 1605$

7. Reisch J, Khaled SA, Szendrei K, Novak I (1975) Phytochemistry 14:1137-1138

8. Lisec J, Schauer N, Kopka J, Willmitzer L, Fernie AR (2006) Nat Protoc 1:387

9. Monton MRN, Soga T (2007) J Chromatogr A 1168:237

10. Bajad SU, Lu WY, Kimball EH, Yuan J, Peterson C, Rabinowitz JD (2006) J Chromatogr A 1125:76

11. Albert K (ed)(2002) On-line LC-NMR and related techniques. Wiley, Chichester

12. Lewis IA, Schommer SC, Hodis B, Robb KA, Tonelli M, Westler WM, Suissman MR, Markley JL (2007) Anal Chem 79:9385

13. Holtin K, Kuehnle M, Rehbein J, Schuler P, Nicholson G, Albert K (2009) Anal Bioanal Chem 395:1613-1622

14. Want EJ, Cravatt BF, Siuzdak G (2005) Chembiochem 6:1941
15. Kimball E, Rabinowitz JD (2006) Anal Biochem 358:273

16. Want EJ, Nordstrom A, Morita H, Siuzdak G (2007) J Proteom Res 6:459

17. Rabinowitz JD (2007) Exp Rev Proteom 4:187

18. Rabinowitz JD, Kimball E (2007) Anal Chem 79:6167

19. Albert K, Bayer E (1992) Patonay G (ed) High-performance liquid chromatography proton nuclear magnetic resonance on-line coupling. VCH, New York, pp 197-229

20. Grynbaum MD, Meyer C, Putzbach K, Rehbein J, Albert K (2007) J Chromatogr A 1156:80-86

21. Grynbaum MD, Kreidler D, Rehbein J, Purea A, Schuler P, Schaal W, Czesla H, Webb A, Volker S, Albert K (2007) Anal Chem 79:2708-2713

22. Shadomy S, Pfalle MA (1991) Manual of clinical microbiology, 5th edn. American Society for Microbiology, Washington

23. National Committee for Clinical Laboratory Standards (1998) Performance standards for antimicrobial susceptibility tests, 6th edn (approved standard; document M2-A6, vol. 18, no. 1). National Committee for Clinical Laboratory Standards, Villanova

24. Pfaller MA, Boyken L, Messer SA, Hollis RJ, Diekema DJ (2004) J Clin Microbiol 42:1288-1289

25. Raitza M, Pursch M, Strohschein S, Albert K, Sander LC (1998) GIT Lab J 2:237-241

26. Albert K, Händel H, Pursch M, Strohschein S (1996) In: Pesek JJ, Matyska MT, Abuelafiya RR (eds) Chemically modified surfaces, vol. 6. The Royal Society of Chemistry, Cambridge, pp 30-44

27. Albert K, Schlotterbeck G, Braumann U, Händel H, Spraul M, Krack G (1995) Angew Chem Int Ed Engl 34:1014-1016

28. Kühnle M, Holtin K, Kreidler D, Czesla H, Schurig V, Schuler P, Schaal W, Albert K (2008) Anal Chem 80:5481-5486

29. Albert K, Braumann U, Tseng LH, Nicholson G, Bayer E, Spraul M, Hofmann M, Dowle C, Chippendale M (1994) Anal Chem 66:3042-3046

30. Albert K (1995) Angew Chem Int Ed Engl 34:641-642

31. Waridel P, Wolfender JL, Lachavanne JB, Hostettmann K (2004) Phytochemistry 65:945

32. Bringmann G, Messer K, Wohlarth M, Kraus J, Dumbuya K, Rueckert M (1999) Anal Chem 71:2678

33. Bringmann G, Wohlfarth M, Rischer H, Schlauer J, Brun J (2002) Phytochemistry 61:195-204

34. Schneider B, Paetz C, Hölscher D, Opitz Stefan (2005) Magn Reson Chem 43:724-728

35. Schneider B, Gershenzon J, Graser G, Hölscher D, Schmitt B (2003) Phytochem Rev 2:31-43

36. Sprogøe K, Stærk D, Ziegler HL, Jensen TH, Holm-Møller SB, Jaroszewski JW (2008) J Nat Prod 71:516-519 